\title{
A CONSTITUCIONALIZAÇÃO SIMBÓLICA DA EMENDA CONSTITUCIONAL No 81/2014 E A VIDA NUA DO TRABALHADOR ESCRAVO NO BRASIL
}

\author{
THE SYMBOLIC CONSTITUTIONALISATION OF THE \\ CONSTITUTIONAL AMENDMENT \# 81/2014 AND THE BARE LIFE OF \\ THE SLAVE LABORER IN BRAZIL
}

\author{
José Lucas Santos Carvalho \\ Universidade Federal de Sergipe - UFS - (São Cristóvão, SE, Brasil) \\ Flávia de Ávila \\ Universidade Federal de Sergipe - UFS - (São Cristóvão, SE, Brasil)
}

Recebimento: 19 ago. 2017

Aceitação: 5 out. 2017

\begin{abstract}
Como citar este artigo / How to cite this article (informe a data atual de acesso / inform the current date of access):
CARVALHO, José Lucas Santos; ÁVILA, Flávia de. A constitucionalização simbólica da Emenda Constitucional No 81/2014 e a vida nua do trabalhador escravo no Brasil. Revista da Faculdade de Direito UFPR, Curitiba, PR, Brasil, v. 62, n. 3, p. 267-284, set./dez. 2017. ISSN 2236-7284. Disponível em: <http://revistas.ufpr.br/direito/article/view/54646>. Acesso em: 21 dez. 2017. DOI: http://dx.doi.org/10.5380/rfdufpr.v62i3.54646.
\end{abstract}

\section{RESUMO}

A Emenda Constitucional n ${ }^{\circ}$ 81/2014 determinou a expropriação de bens oriundos da exploração do trabalho escravo. No entanto, tal alteração é compreendida como uma norma de eficácia contida, que depende de regulação infraconstitucional. Houve, assim, transferência da solução para outro momento, caracterizando-se um ato de constitucionalização simbólica como fórmula de compromisso dilatório. Paralelamente, no mesmo momento histórico em que se discute no parlamento brasileiro fórmulas para redução do alcance do conceito de escravidão, o Brasil é instado internacionalmente a aprimorar os seus mecanismos de combate à escravidão. Este artigo, utilizando-se do aporte teórico da biopolítica do filósofo Giorgio Agamben, defende que a constitucionalização simbólica é uma ferramenta do poder soberano, no exercício de suas táticas de controle e manutenção de poder sobre a vida. Desse modo, seria mantida a estrutura da sociedade brasileira baseada em um controle biopolítico de exclusão-inclusão do sujeito vivente - no caso, o trabalhador escravo -, consolidando, assim, a vida nua na sociedade contemporânea.

\section{PALAVRAS-CHAVE}

Constitucionalização simbólica. Trabalho escravo. Vida nua.

\begin{abstract}
The Brazilian constitutional amendment \# 81/2014 predicted the expropriation of goods derived from the exploitation of slave labor. Nevertheless, such alteration is understood as a norm of contained efficacy that depends on infraconstitutional regulation. Therefore, there was a transfer of the solution to another moment to characterize a symbolic constitutionalisation as a formula of dilatory commitment. At the same time, the Brazilian parliament seeks to reduce the scope of the concept of slavery and Brazil is urged internationally to improve its mechanisms to combat slavery. This article,
\end{abstract}


using the theoretical contribution of the philosopher Giorgio Agamben, argues that a symbolic constitutionalisation is a tool of sovereign power, in the exercise of its tactics of control and maintenance of power over a life, to maintain the structure of Brazilian society based on a biopolitical control of exclusion-inclusion of the living subject, in this case, the slave laborer thus consolidating bare life in contemporary society.

\section{KEYWORDS}

Symbolic constitutionalisation. Slave labor. Bare life.

\section{INTRODUÇÃO}

Apesar de o Trabalho Escravo Contemporâneo (TEC) ${ }^{1}$ ser juridicamente proibido, sendo objeto de normas internacionais e considerado uma norma imperativa do Direito Internacional (jus cogens) que implica obrigações erga omnes para os Estados, a exploração intensiva e violenta do trabalho humano é um fenômeno social global que, de acordo com o Global Slavery Index 2016, atinge cerca de 45.800 .000 pessoas, quase $0,5 \%$ da população mundial (WALK FREE FOUNDATION, 2016). No Brasil, segundo dados do Ministério do Trabalho e Emprego (MTE), em 2016, durante operações de fiscalização para erradicação do trabalho escravo, 885 trabalhadores foram resgatados “em condições análogas à de escravo” (BRASIL, 2016).

Contemporaneamente, para determinar uma situação como escravidão é necessário analisar um conjunto de características que não se limitam ao exercício dos atributos do direito de propriedade que está adstrito ao conceito tradicional de escravidão ou chattel (CORTE INTERAMERICANA DE DIREITOS HUMANOS, 2016, p. 71), havendo uma diversidade de termos para caracterizar a situação e uma variação de sentidos, que constitui um campo político-ideológico de construção do conceito no âmbito internacional e interno ${ }^{2}$. Para compreender o significado de TEC exigem-se dois elementos fundamentais: o estado ou condição de um indivíduo e o exercício de algum dos atributos do direito de propriedade, isto é, que o escravizador exerça poder sobre a pessoa escravizada a ponto de controlar sua autonomia individual, colocanda-o em completa vulnerabilidade. Para Bales (2012, p. 280), o escravo é pessoa - homem, mulher ou criança - mantida nesta condição por meio da violência ou ameaça de violência, para fins de exploração econômica. As formas dessa exploração

\footnotetext{
${ }^{1}$ Neste trabalho, optou-se por utilizar a expressão Trabalho Escravo Contemporâneo (TEC), pois este termo efetivamente dimensiona o problema ao explicitar que as variadas formas de exploração na atualidade constituem trabalho escravo, esclarecendo-se o debate político em torno do tema que tanto fragiliza o enfrentamento da escravidão.

${ }^{2}$ Coexistem na literatura nacional e internacional outras denominações da expressão "trabalho escravo contemporâneo": “trabalho clandestino”, “condições análogas à escravidão”, “trabalho forçado”, “nova escravidão”, “trabalho precário”, “trabalho ilegal” e "subtrabalho”. Sobre o tema, Sousa (2015, p. 86) alerta que ainda não há consenso sobre o uso das terminologias e que, no próprio âmbito da Organização Internacional do Trabalho, ainda há diferenças consideráveis em relação ao significado atribuído a elas.
} 
são variadas e envolvem a prostituição forçada, a pornografia, a venda de órgãos, a servidão, a servidão por dívida ou o uso de seres humanos em conflitos armados.

De acordo com a Corte Interamericana de Direitos Humanos (Corte IDH), no julgamento do Caso “Trabalhadores da Fazenda Brasil Verde contra a República Federativa do Brasil”3, para determinar uma situação como escravidão contemporânea é necessário o preenchimento de alguns atributos. Os critérios compreendem a restrição ou controle da autonomia individual; a perda ou restrição da liberdade de movimento; a obtenção de um benefício por parte do perpetrador; a ausência de consentimento ou de livre arbítrio da vítima, ou sua impossibilidade ou irrelevância devido à ameaça de uso da violência ou outras formas de coerção, o medo de violência, fraude ou falsas promessas; o uso de violência física ou psicológica; a posição de vulnerabilidade; a detenção ou cativeiro; e a exploração.

No Brasil, após 15 anos de tramitação da Proposta de Emenda à Constituição nº 57A/1999, a Emenda Constitucional n ${ }^{\circ}$ 81, de 5 de junho de 2014, deu nova redação ao artigo 243 da Constituição Federal. Tal alteração acrescentou como possibilidade o confisco de qualquer bem de valor econômico que utilize a exploração de trabalho escravo ${ }^{4}$; no entanto, esta modificação é compreendida como uma norma de eficácia contida, ao estabelecer que o procedimento ocorrerá “na forma da lei”.

Para Marcelo Neves (1994), a constitucionalização simbólica é um fenômeno de produção do texto normativo, revelando que o sentido político prevalece hipertrofiado em relação ao aparente sentido normativo-jurídico. Desse modo, as declarações de direitos, apesar de sua previsão em disposição legal, encontram-se em descompasso com a realidade social e com o próprio sistema constitucional. Segundo o autor, esse fenômeno pode ser para: a) confirmar valores sociais; b) demonstrar a capacidade de ação do Estado; ou c) adiar a solução de conflitos sociais mediante compromissos dilatórios. Assim, dentre as possibilidades de o Estado legislar simbolicamente, configura-se aquela em que o Estado objetiva criar a imagem de que responde normativamente às

\footnotetext{
${ }^{3}$ O caso “Trabalhadores da Fazenda Brasil Verde contra a República Federativa do Brasil”, julgado em 2016, é o primeiro caso de escravidão contemporânea e de tráfico de pessoas julgado pela Corte IDH e a quinta condenação do Estado brasileiro na Corte. O conceito de TEC estabelecido pelo Tribunal foi construído a partir da análise da jurisprudência internacional sobre a matéria e dos tratados internacionais, encontrando-se a definição em consonância com a maior proteção ao indivíduo (princípio pro persona).

4 “Art. 243. As propriedades rurais e urbanas de qualquer região do País onde forem localizadas culturas ilegais de plantas psicotrópicas ou a exploração de trabalho escravo na forma da lei serão expropriadas e destinadas à reforma agrária e a programas de habitação popular, sem qualquer indenização ao proprietário e sem prejuízo de outras sanções previstas em lei, observado, no que couber, o disposto no art. $5^{\circ}$.

Parágrafo único. Todo e qualquer bem de valor econômico apreendido em decorrência do tráfico ilícito de entorpecentes e drogas afins e da exploração de trabalho escravo será confiscado e reverterá a fundo especial com destinação específica, na forma da lei.”
} 
dificuldades da sociedade, embora as respectivas relações sociais não sejam realmente normatizadas de maneira a modificar a realidade, deixando para tempo futuro e incerto a solução do problema social.

Foi na perspectiva de "legislação como fórmula de compromisso dilatório", no sentido apresentado por Neves (1994), que a Emenda Constitucional n ${ }^{\circ}$ 81/2014 entrou em vigor, pois o seu conteúdo apenas transfere a solução do conflito para outro momento. Além disso, paralelamente à aprovação da Emenda, iniciou-se um movimento no Legislativo para modificar o conceito de “escravidão”, reduzindo a abrangência conceitual do crime previsto no art. 149 do Código Penal, este em consonância com os instrumentos internacionais de proteção aos direitos humanos.

Diante desta situação de exclusão da dignidade humana, valor fundamental da Constituição, questiona-se: por que as normas de direitos fundamentais não são cumpridas e se tornam simbólicas? Por que o Estado brasileiro não aprimora os seus mecanismos de combate à escravidão, a exemplo do caso da Emenda Constitucional $n^{\circ}$ 81/2014, que poderia ter uma tutela mais eficiente (eficácia plena), em vez de condicionar a sua aplicação à regulação infraconstitucional?

No presente artigo, utilizando o aporte teórico do filósofo Giorgio Agamben no projeto Homo Sacer, pretende-se demonstrar que não se trata de uma escolha inconsciente do Estado brasileiro, mas de uma prática biopolítica em que o poder soberano, no exercício de suas táticas de controle e manutenção de poder sobre a vida, mantém a estrutura da sociedade brasileira baseada em um controle biopolítico de exclusão-inclusão do sujeito vivente - no caso específico deste estudo, o indivíduo vítima do trabalho escravo.

Com a assunção da biopolítica na contemporaneidade, Agamben (2010) nos explica que o paradigma do poder moderno consiste na "gestão de coisas e pessoas” com o objetivo de produzir sujeitos governáveis a partir da captura de sua subjetividade. A vítima do trabalho escravo tem a sua subjetividade capturada. Encontra-se desnudado de qualquer tutela jurídica, o que o reduz a um corpo “qualquer”, ao portador de uma vida nua, isto é, uma vida política (bíos) reduzida a zoé, vida animal, biológica, a potencialidade do que seria, dentro de toda a sua impotência. O trabalhador escravo é, por assim dizer, um homo sacer, esta figura do direito romano arcaico que representa o caráter sacro da vida humana. Um indivíduo que o povo julgou por algum delito, e não é lícito sacrificá-lo, porém, se alguém o matar, não será condenado por homicídio (AGAMBEN, 2010, p. 79).

A primeira parte deste trabalho terá por escopo apresentar a biopolítica e os conceitos propostos por Agamben para entender o fenômeno do homo sacer na modernidade. O objetivo é compreender como o poder soberano atua no estado democrático de direito, por intermédio da produção normativa simbólica, para exercer o controle sobre a vida. Em seguida, será trabalhado o 
conceito de TEC e exposto o panorama do trabalho escravo no Brasil, bem como o da legislação sobre o tema, para que se possa perceber o uso biopolítico dos direitos fundamentais.

A última seção deste trabalho tratará de elucidar como esta prática de controle sobre a vida ocorre, partindo da hipótese desenvolvida ao longo do texto, de que a constitucionalização simbólica é uma ferramenta do poder soberano para exercer o controle de exclusão-inclusão do sujeito, consolidando, assim, a vida nua na sociedade contemporânea.

Deste modo, para que os questionamentos sejam respondidos, será utilizada, no âmbito da vertente teórico-metodológica das ciências sociais aplicadas, a linha jurídico-teórica, por se aproximar da filosofia do direito, do direito constitucional e da hermenêutica jurídica ao estudar conceitos, interpretação e aplicação de normas. Consequentemente, será adotado o tipo metodológico jurídico-exploratório, pois serão analisados diversos aspectos sobre a temática. Será utilizada, ainda, a técnica de análise de conteúdo de textos doutrinários, acadêmicos e normas legais.

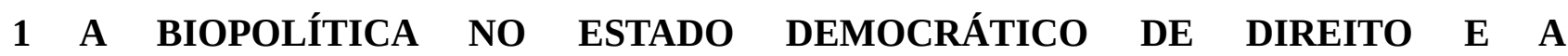 CONSTITUCIONALIZAÇÃO SIMBÓLICA}

Giorgio Agamben (2010, p. 12) afirma que a politização da vida nua é o acontecimento decisivo da modernidade. A vida como uma questão política faz surgir a biopolítica no momento em que o Estado passa a administrar e estabelecer regras sobre a vida do homem, tutelando-a. De acordo com Agamben (2010), foi na Idade Moderna que houve a radicalização da biopolítica, com a entrada da vida do homem e dos processos biológicos inerentes ao ser humano como parte do cálculo do poder, diante da necessidade do Estado em fortalecer a sua força produtiva. Com o argumento de proteção da vida da população, o poder soberano passou a preservar a vida de alguns e a determinar a morte de outros, consistente no direito de vida e de morte, direito de fazer viver ou deixar morrer.

Giorgio Agamben (2010), na série Homo Sacer, estrutura sua análise na distinção entre zoé e bíos, descritos por Aristóteles, que em termos muito resumidos podem ser considerados vida biológica e vida política, respectivamente. Com base nessas duas classificações, Agamben introduz uma terceira, adaptada do ensaio Para uma Crítica da Violência, de Walter Benjamin - a vida nua, que se constitui no novo corpo biopolítico da modernidade, em termos influenciados por Foucault.

A vida nua se dissimula no modelo jurídico-institucional no qual o exercício do poder soberano se consolida, aparecendo invariavelmente quando zoé e bíos são separadas, por meio da desconsideração da bíos ou da mera preservação da zoé. A relação exclusiva-inclusiva proporcionada 
pela linguagem no âmbito das relações intersubjetivas capaz de manter a reflexão sobre o viver dá lugar a um espaço de mera vida, que retira qualquer possibilidade de existência de singularidades em meio a um simulacro de sacralidade da vida.

Consequentemente, no vocabulário atribuído a direitos humanos, a vida nua, usada como estratégia de poder, é debilmente preservada por normativas que carecem de efetividade por traduzirem conceitos desprovidos de conteúdo material, em razão de estarem ligados não a direitos, mas a excepcionalidades. Infelizes exemplos de quando a excepcionalidade vira regra são os trabalhadores escravos contemporâneos.

Neste sentido, Agamben sugere haver a noção de bando que, por si só, significa a existência de um paradoxo: é, ao mesmo tempo, o ato do poder soberano incluir no âmbito da legislação alguém que será, por esta razão, excluído de sua comunidade, como o trabalhador escravo. Aplicando-se a lei, que não lhe garante direitos, mas excepcionalidades, excluem-se os indivíduos que são despersonalizados ante a sua comunidade, o que os torna incluídos-excluídos.

Foucault (1975) explica que, com a constituição do Estado Moderno e o surgimento das relações da sociedade capitalista, adveio a necessidade de uma tecnologia de poder para gerir e controlar as vidas humanas. Todavia, o exercício do poder não é somente do Estado, apesar de tradicionalmente atribuir-se a ele o seu monopólio. Em suas investigações, Foucault (1975) verificou o poder como uma rede de micropoderes articulados ao Estado e que permeiam toda a estrutura social, entendendo como essas microestruturas se relacionam com o poder estatal. Nessa perspectiva foucaultiana, as relações de poder ultrapassam a dimensão estatal e estão em toda a sociedade. O poder, então, penetra em instituições e corporifica-se em técnicas que controlam a vida dos indivíduos.

Ora, o estudo desta microfísica supõe que o poder nela exercido não seja concebido como
uma propriedade, mas como uma estratégia, que seus efeitos de dominação não sejam
atribuídos a uma "apropriação", mas a disposições, a manobras, a táticas, a técnicas, a
funcionamentos; que se desvende nele antes uma rede de relações sempre tensas, sempre em
atividade, do que um privilégio que se pudesse deter; que se seja dado como modelo antes a
batalha perpétua do que o contrato que faz uma cessão ou uma conquista que se apodera de
um domínio. Temos, em suma, de admitir que esse poder se exerce mais do que se possui,
que não é "privilégio" adquirido ou conservado da classe dominante, mas o efeito de conjunto
de suas posições estratégicas - efeito manifestado e às vezes reconduzido pela posição dos
que são dominados. (FOUCAULT, 1975, p. 29).

Nos modernos Estados democráticos de direito, uma técnica biopolítica de poder são as declarações dos direitos. Agamben explica que elas são o local da passagem da forma clássica da soberania de origem divina à nova figura da soberania dos Estados de direito. Neles, o indivíduo passa de súdito a cidadão. 
[as declarações de direito] asseguram a exceptio da vida na nova ordem estatal que deverá suceder à derrocada do ancien régime. Que, através dela, o "súdito" se transforme, como foi observado, em "cidadão”, significa que o nascimento - isto é, a vida nua natural como tal torna-se aqui pela primeira vez (com uma transformação cujas conseqüências biopolíticas somente hoje podemos começar a mensurar) o portador imediato da soberania. (AGAMBEN, 2010, p. 135).

O sociólogo Eugène Enriquez (2006), propondo uma visão trágica da vida 5 , explica que o sujeito histórico, aquele que contribui para definir a orientação da sociedade, surgiu na aurora do século $\mathrm{V}$ a.C., em Atenas, com a ideia do cidadão. Tal noção apagou-se nos períodos feudais e monárquicos, e reacendeu com a Carta de direitos da Inglaterra e as Revoluções Francesa e Americana. Para ser histórico, o indivíduo necessitaria, então, ter direitos, ser alguém que desfruta dos direitos e que está sob a proteção de uma lei em estado de isonomia, mas não foram todos os cidadãos que receberam os atributos da cidadania.

Pode-se dizer, então, que o poder soberano divide a sociedade entre aqueles aptos a exercerem a sua cidadania e os impossibilitados a tais direitos, apesar de teoricamente serem sujeitos desses mesmos direitos. Agamben (2010) afirma que na "biopolítica moderna soberano é aquele que decide sobre o valor ou sobre o desvalor da vida enquanto tal” (AGAMBEN, 2010, p. 149). É no controle biopolítico do direito de vida e de morte que está a figura do homo sacer.

O homo sacer, do antigo direito romano, é um indivíduo não sacrificável e, ao mesmo tempo, matável - o homem sacro, por estar destituído completamente da condição humana de protegido pelo direito. Uma figura jurídico-política pela qual uma pessoa, ao ser proclamada sacer, era legalmente excluída do direito. Esta condição impedia-o de ser legalmente morto (sacrificado), porém qualquer um podia matá-lo, pois a lei não punia por isso. Beek (2012) ensina que, no arcaico direito romano, a frase sacer esto era usada em fontes religiosas e seculares, indicando uma penalidade por um erro cometido.

Agamben (2010) utiliza-se dessa figura histórica para afirmar que homo sacer é a vida abandonada pelo direito, a vida nua. Nesse contexto, o corpo é o elemento primordial da estratégia política do soberano, pois ao tomá-lo sem identidade jurídica, demonstra com clareza que a bíos, como a vida política, fora reduzida à zoé, aqui como vida animal, biológica.

O que homo sacer revela é a existência do soberano como figura essencial do direito ocidental e da sua ordem política. O soberano existe porque tem o poder de decretar a exceção do direito, ou seja, suspender o direito para decretar a existência da vida nua. Só um poder soberano, que esteja fora da ordem e acima do direito, tem o poder de decretar a suspensão

\footnotetext{
${ }^{5}$ Nas palavras do autor: "Proponho, pois, uma visão trágica da vida, não para nos deixar invadir pela fatalidade, mas para examinar lucidamente se uma outra via é possível, se podemos fazer prevalecer a civilização, apesar das ambiguidades, sobre a barbárie” (ENRIQUEZ, 2006, p. 2).
} 
do direito para os outros. (RUIZ, 2011).

Em um estado democrático de direito, homo sacer refere-se à vida abandonada, ao sujeito que vive à margem da sociedade. A precarização das condições de vida, a marginalização de uns e o assassinato de outros, o alijamento de todos os direitos previstos na Constituição e documentos internacionais de direitos humanos são produções contínuas de vidas nuas, sujeitos expostos à violência e à miséria. Esta é a face crua do Estado que prioriza o discurso normativo-jurídico dos direitos, assumindo um caráter simbólico, em detrimento da sua implementação. Na sociedade brasileira, a vida nua é representada por este indivíduo destituído de direitos, cuja realidade não é alcançada pela normatização simbólica, para que direitos e garantias fundamentais constem somente "no papel”.

Giacoia Junior (2008) afirma que, para Agamben, as declarações de direitos podem e devem ser entendidas tanto como mecanismo de asseguramento dos direitos individuais e liberdades públicas, quanto como um instrumento de ressignificação e investimento jurídico-político da vida no arcabouço institucional do Estado-nação. Ao realizar uma crítica radical sobre os direitos humanos, Giacoia Junior (2008) assevera que é a sacralidade, comum ao homo sacer e ao caráter sagrado dos direitos humanos, que institui uma insidiosa cumplicidade entre a vida nua e o poder biopolítico do direito.

Marcelo Neves (2005, p. 421) indica que a força simbólica dos direitos expressa uma ambivalência, no sentido de que os textos (declarações, tratados, constituições, por exemplo) servem à manutenção do status quo de carência dos direitos, bem como à superação de situações concretas de negação dos direitos. Nessa perspectiva, constitucionalizar direitos serve não somente como mecanismo de arrefecimento das mobilizações sociais, mas também como combustível de mudança para aqueles que ainda conseguem lutar contra a opressão, em um sistema que busca reduzi-los à vida nua.

Gontijo e Arcelo (2009) analisam o discurso dos direitos sob a ótica foucaultiana e consideram como mecanismo de governamentalidade biopolítica as normas de direitos fundamentais. Segundo os autores, essas normas se tornam simbólicas porque ocupam o espaço político de declaradores de direitos, mas, na práxis, são normas protelatórias, “capazes de dissimular e arrefecer os movimentos sociais que as exigem” (2009, p. 5889). É neste sentido que reside a força simbólica das declarações de direitos.

Assim a análise do discurso dos direitos por meio da governamentalidade biopolítica aponta para uma interpretação que busca problematizar a superação da força simbólica dos direitos enquanto estratégias de dominação e de exclusão dos cognitivamente ambivalentes, isto é, 
dos economicamente desengajados, tidos como inúteis, logo inimigos que precisam ser afastados ou até sofrer a vida matável dos anormais. (GONTIJO; ARCELO, 2009, p. 5.898).

Quando analisa a constitucionalização simbólica, Marcelo Neves aborda o significado social e político dos textos constitucionais, exatamente na relação inversa da sua concretização jurídiconormativa. Ao abordar os efeitos sociais da constitucionalização ineficaz, o autor discute a função simbólica de textos constitucionais carentes de concretização normativo-jurídica, especialmente em uma sociedade em que amplos setores da população dependem das mais diversas prestações do Estado, mas não têm acesso a elas. Ao texto constitucional simbolicamente includente contrapõe-se a realidade constitucional excludente. $\mathrm{O}$ autor nos explica que ideias estruturantes da linguagem constitucional, como os direitos fundamentais, a tripartição dos poderes, o processo eleitoral e a concepção de isonomia, são deturpadas na práxis do processo concretizador (NEVES, 1994, p. 91).

É sabido que, na modernidade, a constituição é compreendida como carta de liberdade ou pacto de poder, sendo o vínculo estrutural entre política e direito (NEVES, 1994). Ao apresentar as concepções de constituição, Marcelo Neves explica que Lassale não observou que os fatores “materiais” de poder e a ordem "jurídica” constitucional se encontram em relações permanentes de implicação recíproca, nesta relação entre política e direito.

O discurso dos direitos, segundo Marcelo Neves, emerge no contexto do dissenso estrutural que advém da sociedade moderna. Assim, a aparência trazida pela constitucionalização, enquanto representação ilusória, é método de imunização do sistema político contra alternativas de consonância do texto constitucional com a realidade. Neste panorama, os direitos humanos e fundamentais devem promover a convivência nas condições reais de dissenso estrutural. Desse modo, por meio da institucionalização de direitos fundamentais, "a Constituição reconhece a supercomplexidade da sociedade, a dissolução de critérios socialmente globalizantes de orientação das expectativas, a inexistência de um sistema social supremo” (NEVES, 1994, p. 70).

No entanto, a dissonância entre o texto da Constituição e a realidade social brasileira denuncia um sistema de violência em face dos indivíduos mais vulneráveis. A rede de poder, na perspectiva foucaultiana, atua na manutenção do status quo e o exercício do poder soberano controla vidas nuas, tornando-as inúteis e descartáveis. Em um país que se quer democrático, o trabalho escravo é uma forma de violência que retira do sujeito todos os direitos que as declarações de direitos humanos e a Constituição lhe asseguram.

Em virtude dos compromissos internacionais assumidos pelo País e da própria obrigação estabelecida constitucionalmente, o Estado brasileiro vê-se compelido a adotar medidas de combate ao trabalho escravo. Todavia, a sua atuação é controlada por agentes políticos e econômicos que 
influenciam diretamente nas decisões do Estado. Diante disso, a exploração do trabalho escravo se mantém, descartando vidas, e os sujeitos que compõem a rede de poder continuam com o lucro da exploração violenta da vida humana.

\section{O CENÁRIO DO TRABALHO ESCRAVO NO BRASIL E A EMENDA CONSTITUCIONAL No 81/2014 COMO UM CASO DE CONSTITUCIONALIZAÇÃO SIMBÓLICA}

O compromisso do Estado brasileiro em enfrentar o trabalho forçado está na Constituição Federal, que, em seu artigo $5^{\circ}$, inciso III, determina que ninguém será submetido a tratamento desumano ou degradante, a exemplo das formas contemporâneas de escravidão, bem como nos direitos sociais previstos nos artigos $6^{\circ}$ e $7^{\circ}$, que asseguram a garantia do trabalho decente, antítese do trabalho escravo. Outrossim, o compromisso internacional do País em enfrentar o trabalho forçado existe desde a sua adesão à Organização Internacional do Trabalho (OIT), que possui, entre os princípios fundamentais e os fins gerais, definidos na Declaração da Filadélfia de 1944, a erradicação do trabalho escravo, além de o País ter ratificado posteriormente diversos tratados internacionais de direitos humanos e de direito internacional do trabalho, a exemplo das Convenções n ${ }^{\circ} 29^{6}$ e $105^{7}$.

O trabalho escravo, que é um problema global ${ }^{8}$, foi reconhecido oficialmente pelo Estado brasileiro, em 1995, perante a OIT, como um grave problema social e, desde então, o País reformulou seu sistema de combate à escravidão. Para isto, criou o Plano Nacional de Combate ao Trabalho Escravo, o Pacto Nacional de Combate ao Trabalho Escravo, instalou a Comissão Nacional para Erradicação do Trabalho Escravo (Conatrae) e suas respectivas comissões estaduais, criou Grupos Móveis de Fiscalização e implementou a chamada "lista suja” (ORGANIZAÇÃO INTERNACIONAL DO TRABALHO, 2010). Tal lista, criada em 2004 pela Portaria 540 do Ministério do Trabalho e Emprego, é um cadastro de empregadores infratores flagrados pela fiscalização explorando mão de obra escrava (ORGANIZAÇÃO INTERNACIONAL DO TRABALHO, 2010) ${ }^{9}$.

\footnotetext{
${ }^{6}$ Convenção concernente a Trabalho Forçado ou Obrigatório, adotada pela Conferência em sua Décima Quarta Sessão Genebra, 28 de junho de 1930 (com as modificações da Convenção de Revisão dos artigos finais, de 1946).

${ }^{7}$ Convenção $n^{\circ} 105$, concernente à abolição do trabalho forçado adotada pela Conferência em sua quadragésima sessão Genebra, 25 de junho de 1957.

${ }^{8}$ De acordo com a ONU (2016), a região do planeta com a maior prevalência de trabalho escravo (definida como o número de vítimas por mil habitantes) é o centro e sudeste da Europa (compostos por países que não integram a União Europeia) e a Comunidade de Estados Independentes (4,2 por 1.000 habitantes). Em seguida, estão África (4 por 1.000 habitantes), Oriente Médio (3,4 por 1.000 habitantes), Ásia-Pacífico (3,3 por 1.000 habitantes), América Latina e Caribe (3,1 por 1.000 habitantes) e, por fim, as economias desenvolvidas e a União Europeia (1,5 por 1.000 habitantes).

${ }^{9}$ Portaria $n^{\circ}$ 540, de 15 de outubro de 2004, do Ministério do Trabalho e Emprego. “Art. $1^{\circ}$ Criar, no âmbito do Ministério do Trabalho e Emprego - MTE, o Cadastro de Empregadores que tenham mantido trabalhadores em condições análogas à de escravo.
} 
As empresas constantes desse cadastro foram listadas e divulgadas à sociedade, como mecanismo de transparência, a fim de permitir que outras ações fossem adotadas, tais como o comprometimento da venda de seus produtos a partir da avaliação da sociedade e o próprio cancelamento de contratos com fornecedores. O referido cadastro foi reconhecido internacionalmente como um mecanismo eficaz de fiscalização do trabalho escravo.

Todavia, em dezembro de 2014, durante o recesso judicial, uma liminar do então presidente do Supremo Tribunal Federal, Ricardo Lewandowski, suspendeu sua publicação. A decisão foi concedida no bojo da Ação Direta de Inconstitucionalidade (ADIn) n 5.209, ajuizada pela Associação Brasileira de Incorporadoras Imobiliárias (Abrainc), que sustentou a inconstitucionalidade da Portaria Interministerial do Ministério do Trabalho e da Secretaria de Direitos Humanos, MTE/SDH n 2, de 12 de maio de 2011, e da Portaria MTE n 540, de 19 de outubro de 2004, por substituírem competência legislativa do Congresso Nacional, além de o procedimento de inclusão violar o devido processo legal (BRASIL, 2016).

A resolução da controvérsia somente aconteceu em maio de 2016, quando a ministra Cármen Lúcia, relatora da ADIn, julgou a ação e reconheceu a perda de seu objeto porque duas portarias interministeriais posteriores acabaram por revogar a norma impugnada e alteraram substancialmente o conteúdo das normas que originaram a ação.

A criação da "lista suja” tem efeitos simbólicos e efetivos. Primeiramente, produz o efeito de que esses direitos existem e devem ser reconhecidos. Segundo, sugere que há consequências reais à sua violação. Entretanto, a dinâmica da rede de poder, que há na tensão entre política e direito, tem no poder econômico um forte agente de influência nas decisões do Estado, criando ainda mais violações de direitos e impedindo o avanço de pautas sociais que atendam àqueles que são impedidos do gozo dos direitos, criando e mantendo a vida nua.

Outro avanço que foi reconhecido como vanguardista pela Organização das Nações Unidas (ONU) refere-se à atualização, em 2003, da legislação criminal para introduzir o conceito moderno de trabalho escravo ${ }^{10}$, o qual está alinhado com as discussões internacionais sobre o tema, o que envolve não somente a restrição de liberdade e a servidão por dívidas, mas outros atos que violam a dignidade do indivíduo. No Código Penal, há o esclarecimento de que reduzir alguém à condição

Art. $2^{\circ}$ A inclusão do nome do infrator no Cadastro ocorrerá após decisão administrativa final relativa ao auto de infração lavrado em decorrência de ação fiscal em que tenha havido a identificação de trabalhadores submetidos a condições análogas à de escravo.” (BRASIL, 2004).

${ }^{10}$ De acordo com o artigo 149 do Código Penal brasileiro, o crime de redução a condição análoga à de escravo é definido como "reduzir alguém a condição análoga à de escravo, quer submetendo-o a trabalhos forçados ou a jornada exaustiva, quer sujeitando-o a condições degradantes de trabalho, quer restringindo, por qualquer meio, sua locomoção em razão de dívida contraída com o empregador ou preposto”. 
análoga à de escravo é não somente a privação de liberdade, mas também a exposição às situações nas quais é impossível garantir sua dignidade.

Há quatro tipos de crimes relacionados ao "trabalho análogo ao de escravo", a saber: a submissão de uma pessoa a trabalhos forçados (como caracterizado na Convenção n 29 da OIT); a imposição de jornadas de trabalho exaustivas; a sujeição de alguém à realização de trabalhos em condições degradantes e a submissão de um indivíduo a uma dívida fraudulenta diretamente relacionada com a execução do trabalho. Sobre a inserção no tipo penal do termo "condições degradantes de trabalho”, reflete Sousa (2015, p. 114):

\begin{abstract}
A inserção da "dignidade humana”, degradante, no conceito é resultado de um histórico das relações trabalhistas, com posições plenamente definidas: dominantes e dominados. Estas posições historicamente construídas superam o fator físico humano e adentram no fator cognitivo cristalizando, intuitivamente, uma forma de dominação material e mental. Contribuindo, assim, para que os seres humanos colocados em condições degradantes de trabalho acreditem que a sua única utilidade no mundo é exercer a sua força de trabalho em prol do seu empregador.
\end{abstract}

O conceito de escravidão alarga-se para compreender as condições degradantes de trabalho, isto é, quando a violação de direitos fundamentais coloca em risco a saúde e a vida do trabalhador, e a jornada exaustiva, situação em que a pessoa é submetida a esforço excessivo ou sobrecarga que implica danos à sua saúde ou risco de morte.

Porém, há um esforço de revisar a legislação atualmente vigente sobre o trabalho escravo, a exemplo do Projeto de Lei n ${ }^{\circ}$ 432/2013, em trâmite no Senado Federal, de autoria da Comissão Mista do Congresso Nacional presidida pelo Senador Romero Jucá (Partido do Movimento Democrático Brasileiro - PMDB) e pelo Deputado Federal Cândido Vaccarezza (Partido dos Trabalhadores - PT), que pretende restringir o conceito de TEC para incidir apenas nas hipóteses de cerceamento da liberdade do trabalhador. Assim, o avanço legislativo alcançado com a alteração no Código Penal em $2003^{11}$ no tocante a inclusão das condições degradantes ou jornadas exaustivas estariam de fora do conceito.

Projeto de Lei ${ }^{\circ}$ 432/2013.

Art. $1^{\circ}[\ldots] \S 1^{\circ}$ Para fins desta Lei, considera-se trabalho escravo:

I - a submissão a trabalho forçado, exigido sob ameaça de punição, com uso de coação, ou que se conclui de maneira involuntária, ou com restrição da liberdade pessoal.

II - o cerceamento do uso de qualquer meio de transporte por parte do trabalhador, com o fim de retê-lo no local de trabalho;

\footnotetext{
${ }^{11}$ A redação atual do crime de “redução a condição análoga à de escravo”, dada pela Lei no 10.803 , de 11 de dezembro de 2003, ocorreu no bojo de ações adotadas pelo Estado brasileiro após a solução amistosa alcançada pelo País perante a Comissão Interamericana de Direitos Humanos no “Caso José Pereira” (Petição n 11.289, Informe no 95/03 da Comissão Interamericana de Direitos Humanos), em que o Estado, entre os compromissos assumidos, obrigou-se a realizar modificações legislativas para aprimorar a legislação nacional de combate ao trabalho escravo.
} 
III - a manutenção da vigilância ostensiva no local de trabalho ou a apropriação de documentos ou objetos pessoais do trabalhador, com o fim de retê-lo no local de trabalho; e IV - a restrição, por qualquer meio, da locomoção do trabalhador em razão da dívida contraída com empregador ou preposto.

$\S 2^{\circ} \mathrm{O}$ mero descumprimento da legislação trabalhista não se enquadra no disposto no $\S 1^{\circ}$. (BRASIL, 2013).

Estas discussões que pretendem enfraquecer o combate ao trabalho escravo no País ocorrem capitaneadas por um grupo de parlamentares que ficou conhecido na prática política como "bancada ruralista”. A pesquisadora Sandra Costa (2012) explica que a "bancada ruralista” é formada por um conjunto de políticos empresários da indústria ou do comércio, proprietários de terras (grileiros e latifundiários), que defendem interesses como a aprovação de recursos do orçamento público, obras de infraestrutura e crédito rural para a produção de commodities, sendo esta uma das principais resistências à reforma agrária ${ }^{12}$ no Brasil.

Em sua pesquisa, Sandra Costa (2012) afirma que a presença da bancada traz entraves para a diminuição da concentração de terra e para o reconhecimento dos direitos quilombolas e indígenas. Foi constatado também o envolvimento de congressistas em casos de flagrante de exploração de trabalho escravo em suas propriedades ${ }^{13}$. Logo, a não efetividade da atuação do Estado, como manifestação do próprio interesse dos sujeitos que o integram, desnuda o indivíduo vítima de trabalho escravo de qualquer tutela jurídica, gerando, por conseguinte, um corpo “qualquer”, inclassificável, uma vida nua desprotegida pelo direito.

Apesar da existência do sistema formalmente criado de responsabilização dos exploradores, a impunidade ainda é regra no País. Nesse sentido, em 2010, a Relatoria Especial da ONU sobre formas contemporâneas de escravidão ressaltou a impunidade “com a qual donos de terras, empresas locais e internacionais, bem como intermediários, conhecidos como 'gatos', são beneficiados” (ORGANIZAÇÃO DAS NAÇÕES UNIDAS, 2016, p. 7). Além disso, em 2012, o Conselho de Direitos Humanos, no âmbito da Revisão Periódica Universal, instou o Brasil a adotar medidas legislativas e mecanismos eficazes para combater com efetividade o trabalho escravo no Brasil. Na visão das Nações Unidas, erradicar o trabalho escravo necessita de uma ação coordenada de todos os países, com medidas eficientes que diminuam as vantagens dos exploradores e mitiguem a vulnerabilidade social das vítimas.

\footnotetext{
${ }^{12}$ Segundo o Estatuto da Terra (artigos $1^{\circ}$ e $2^{\circ}$ ), a reforma agrária é o conjunto de medidas para promover a melhor distribuição da terra mediante modificações no regime de posse e uso, a fim de atender aos princípios de justiça social, desenvolvimento rural sustentável e aumento da produtividade. Também envolve outras questões fundamentais e estratégicas, como soberania alimentar, produção de alimentos e controle territorial.

${ }^{13}$ Entre os parlamentares estudados, Sandra Costa (2012) constatou que cerca de 351 possuem uma totalidade de 863.646 hectares de terras em seus nomes, em nome de seus familiares ou de empresas das quais são proprietários, cotistas ou acionistas, segundo dados obtidos do Instituto Nacional de Colonização e Reforma Agrária (Incra).
} 
Normas simbólicas se caracterizam pela baixa normatividade e, nesse cenário de avanços e retrocessos, desde 1999 tramitava no Congresso Nacional a PEC 57A/1999, com o objetivo de possibilitar a expropriação das terras onde forem encontrados trabalhadores submetidos a condições análogas às de escravo.

Após longo período de tramitação, em 2014 entrou em vigor a Emenda Constitucional n ${ }^{\circ}$ 81, que prevê a expropriação de propriedades urbanas ou rurais nas quais tenha sido constatada a prática de trabalho escravo. Entretanto, foi editada uma norma de eficácia contida, ao estabelecer que o procedimento ocorrerá “na forma da lei”. Ainda não há lei regulamentando o dispositivo; tramitam no Congresso Nacional alguns projetos de lei, como o já comentado PL nº 432/2013, que, a pretexto de regulamentar o artigo 243 da Constituição, diminui a abrangência do conceito de trabalho escravo $^{14}$.

Marcelo Neves (1994) explica que a constitucionalização simbólica é um problema típico do Estado periférico. Na modernidade periférica, o problema estrutural é a falta de autonomia operacional dos sistemas jurídico e político, que são bloqueados externamente por injunções dos demais sistemas sociais, especialmente o econômico. Neves (1994, p. 149-150) utiliza-se da teoria dos sistemas, de Luhman, para explicar a lógica de inclusão-exclusão dos indivíduos no sistema social. Nas palavras do autor, o problema da "marginalidade” ou “exclusão" é um problema de “subintegração” nos sistemas funcionais da sociedade, em que o indivíduo depende do sistema, mas não tem acesso às suas prestações. De outro lado, a "sobreintegração” é o acesso aos benefícios do sistema sem dependência de suas regras e critérios.

A “subintegração” do indivíduo, apresentada por Neves, é a vida nua descrita por Giorgio Agamben. Trata-se do indivíduo excluído da ordem jurídica - no caso brasileiro, é o sujeito vítima do trabalho escravo, o subcidadão, excluído de todos os direitos que, formalmente, o estado democrático de direito lhe garante.

Como ressalta Neves (1994, p. 159), “a prática política e o contexto social favorecem uma concretização restrita e excludente dos dispositivos constitucionais”, sendo a constitucionalização simbólica um mecanismo de controle da vida neste estado biopolítico contemporâneo. Quando o Estado age desta forma, escolhe quem vai viver e quem vai apenas sobreviver.

\footnotetext{
14 “Art. $1^{\circ}$ Os imóveis rurais e urbanos, onde for identificada a exploração de trabalho escravo diretamente pelo proprietário, serão expropriados e destinados à reforma agrária e a programas de habitação popular, sem qualquer indenização ao proprietário que foi condenado, em sentença penal transitada em julgado, pela prática de exploração do trabalho escravo, e sem prejuízo de outras sanções previstas em lei, conforme o art. 243 da Constituição Federal.” (BRASIL, 2013).
} 


\section{A CONSTITUCIONALIZAÇÃO SIMBÓLICA COMO PRÁTICA BIOPOLÍTICA DE CONTROLE SOBRE A VIDA}

O homo sacer é o incluído pela exclusão e excluído de forma inclusiva. Ao ser incluído pelo abandono está exposto à vulnerabilidade de todas as formas de violência. Essa figura paradoxal, utilizada por Giorgio Agamben, revela os dois indivíduos que estão fora e acima da ordem: o homo sacer e o soberano.

A vida humana abandonada pelo direito - o homo sacer - existe porque há uma vontade soberana que tem o poder de suspender a ordem, decretar a exceção e a existência da vida nua. Esta vida nua foi colocada para fora da jurisdição humana, tendo como maior exemplo, trazido por Agamben, a vida no campo de concentração.

O campo é o espaço biopolítico de total controle da vida, “é apenas o local onde se realizou a mais absoluta conditio inhumana que se tenha dado sobre a terra” (AGAMBEN, 2010, p. 162). Se há controle total sobre a vida, podemos ver nos locais de trabalho dos trabalhadores escravos o campo contemporâneo do homo sacer brasileiro, pois o explorador tem sobre a pessoa escravizada o controle da sua autonomia individual, colocando-a em completa vulnerabilidade, impedindo a sua liberdade.

E a manutenção desse controle da vida ocorre cotidianamente pelo poder soberano, seja pela ineficiência das políticas implementadas, seja pela criação de normas jurídicas que pouca efetividade possuem sobre a realidade constitucional, normatizando simbolicamente. Neves (1994) propugna que a constitucionalização simbólica tem uma maior abrangência nas dimensões social, temporal e material. O seu uso arrefece a exigência dos direitos e não modifica a realidade; pelo contrário, torna mais inefetivos os direitos fundamentais do estado de direito.

Gontijo e Arcelo (2009, p. 5.892) veem esta prática da governamentalidade vinculada à defesa do mercado. Nos países em desenvolvimento, a biopolítica é uma política de invisibilidade de cidadãos que vivem em subcidadania; assim, o biopoder nas sociedades capitalistas de grande desigualdade social ainda permanece no campo entre a vida e a morte, que são claramente determinadas pelos interesses patrimonialistas. Desse modo, a manutenção do status quo e a obtenção de lucro é o objetivo fundamental do poder econômico.

O próprio Marcelo Neves afirma que a expansão do sistema econômico, com o seu código binário (ter ou não ter), destrói a autonomia dos sistemas político e jurídico. Nos jogos estratégicos de dominação, a constitucionalização simbólica forja o aparato de proteção de que a maioria dos sujeitos vulneráveis necessita. No caso da exploração do trabalho escravo, uma norma constitucional simbólica mantém o problema social, controlando as vidas nuas, com a construção cotidiana de subcidadãos, de indivíduos completamente excluídos de direitos fundamentais que deveriam criar as 
condições necessárias para a vida digna.

\section{CONCLUSÃO}

Ao retomarmos os questionamentos propostos para este artigo - por que as normas de direitos fundamentais não são cumpridas e se tornam simbólicas e por que o Estado brasileiro não aprimora os seus mecanismos de combate à escravidão, a exemplo do caso da Emenda Constitucional $n^{\circ} 81 / 2014$, que poderia ter uma tutela mais eficiente, criando-se uma norma de eficácia plena, em vez de condicionar a sua aplicação à regulação infraconstitucional - nos vemos diante da necessidade de repensar as possibilidades do estado democrático de direito.

As declarações de direitos têm uma função histórico-política dupla: são emancipadoras, contribuindo para a luta por melhorias de vida da população, e integram os processos de sujeição da vida nua ao poder soberano. Os direitos fundamentais, utilizados nesta segunda função, são normas simbólicas que surgem não para modificar a realidade social; pelo contrário, pretende-se arrefecer as lutas por dignidade e conformar o sujeito na vida de exclusão. O texto constitucional includente contrapõe-se à realidade, excludente e sem a adoção de medidas para iniciar um processo concretizador, inviabilizando os compromissos da Constituição de construir uma sociedade menos desigual.

O estudo da situação dos trabalhadores escravos no Brasil revela uma vida inserida em uma rede de produção sistemática de “vidas matáveis”, vidas nuas, em que a expressão simbólica dos direitos fundamentais não lhes pertence, pois foram excluídos da jurisdição humana. A produção de normas simbólicas surge, então, como mais um mecanismo de controle sobre a vida, na perspectiva biopolítica, contribuindo para a manutenção do status quo, mediante a reprodução da desigualdade social.

\section{REFERÊNCIAS}

AGAMBEN, Giorgio. Homo Sacer. O poder soberano e a vida nua I. Tradução Henrique Burigo. 2. ed. Belo Horizonte: Editora UFMG, 2010.

BALES, Kevin. Disposable People: New slavery in the global economy. 3. ed. Berkeley: University of California Press, 2012.

BEEK, Leon ter. Divine Law and the Penalty of Sacer Esto in Early Rome. In: TELLEGENCOUPERUS, Olga. Law and religion in the Roman Republic. Boston: Brill, 2012. Parte 1, p. 1130. 
BRASIL. Ministério do Trabalho e Emprego. Portaria N 540, de 15 de outubro de 2004. Brasília, DF, Diário Oficial da União, 19 out. 2004.

BRASIL. Ministério do Trabalho e Emprego. Resultados da fiscalização para erradicação do trabalho escravo de 2016. Disponível em: <https://goo.gl/yS5V5i>. Acesso em: 10 jul. 2017.

BRASIL. Senado Federal. Projeto de Lei $\mathbf{n}^{\mathbf{0}}$ 432, de 2013. Dispõe sobre a expropriação das propriedades rurais e urbanas onde se localizem a exploração de trabalho escravo e dá outras providências. Disponível em: <https://goo.gl/PJS3Vq> Acesso em: 21 jan. 2017.

BRASIL. Supremo Tribunal Federal. Ação Direta de Inconstitucionalidade $\mathbf{n}^{0}$ 5209. Associação Brasileira de Incorporadoras Imobiliárias - ABRAINC. Relatora Ministra Carmén Lúcia. Julgamento em 16 maio 2016. Disponível em:<https://goo.gl/2yXskD>. Acesso em: 10 jul. 2017.

CORTE INTERAMERICANA DE DIREITOS HUMANOS. Caso Trabalhadores da Fazenda Brasil verde contra a República Federativa do Brasil. Sentença de 20 de outubro de 2016 (Exceções Preliminares, Fundo, Reparações e Custas). Disponível em: <https://goo.gl/uNzLN5>. Acesso em: 20 fev. 2017.

COSTA, Sandra Helena Gonçalves. A questão agrária no Brasil e a bancada ruralista no Congresso Nacional. 2012. 325 f. Dissertação (Programa de Pós-graduação em Geografia Humana) - Universidade de São Paulo (USP), São Paulo, 2012.

ENRIQUEZ, Eugène. O homem do século XXI: sujeito autônomo ou indivíduo descartável. RAEeletrônica, v. 5, n. 1, art. 10, jan./jun. 2006. Disponível em: <https://goo.gl/023k>. Acesso em: 15 jan. 2017.

FOUCAULT, Michel. Vigiar e Punir. Petrópolis: Vozes, 1975.

GIACOIA JUNIOR, Oswaldo. Sobre direitos humanos na era da bio-política. Kriterion. Revista de Filosofia, online, Belo Horizonte, v. 49, n. 118, dez 2008. Disponível em: <https://goo.gl/WDywd>. Acesso em: 10 jan. 2017.

GONTIJO, Lucas de Alvarenga; ARCELO, Adalberto Antonio Batista. A biopolítica nos Estados Democráticos de Direito: a reprodução da subcidadania sob a égide da constitucionalização simbólica. In: XVIII Congresso Nacional do Conpedi, 2009, São Paulo. Anais do XVIII Congresso Nacional do Conpedi. Disponível em: <https://goo.gl/hp9RBX>. Acesso em: 15 jan. 2017.

NEVES, Marcelo. A Constitucionalização Simbólica. São Paulo: Editora Acadêmica, 1994.

NEVES, Marcelo. A Força Simbólica dos Direitos Humanos. Revista Eletrônica de Direito do Estado - REDE online. Ed. nº 04, out./nov./dez. 2005. Disponível em: <https://goo.gl/knfxjL>. Acesso em: 10 jan. 2017.

ORGANIZAÇÃO DAS NAÇÕES UNIDAS. Trabalho Escravo. Brasília, abril de 2016. Disponível em: <https://goo.gl/KX7wZj>. Acesso em: 20 jan. 2017.

ORGANIZAÇÃO INTERNACIONAL DO TRABALHO. As boas práticas da inspeção do trabalho no Brasil: a erradicação do trabalho análogo ao de escravo. Brasília, 2010. Disponível em: 
<https://goo.gl/hkDZeW>. Acesso em: 30 maio 2017.

RUIZ, Castor. Homo sacer. O poder soberano e a vida nua. 2011. Disponível em: <https://goo.gl/13YsEb> Acesso em: 20 jan. 2017.

SOUSA, Roseane Barcellos Marques. Trabalho escravo contemporâneo e Estado capaz no Brasil. 2015. 181 f. Tese (Doutorado em Administração Pública e Governo) - Escola de Administração de Empresas de São Paulo, FGV, São Paulo, 2015.

WALK FREE FOUNDATION. The Global Slavery Index 2016. Disponível em: $<$ https://goo.gl/jQtBnW>. Acesso em: 10 jul. 2017.

José Lucas Santos Carvalho Mestrando em Direito pela Universidade Federal de Sergipe (UFS). Especialista em Direito Público pela Estácio de Sergipe. Bacharel em Direito pela Universidade Tiradentes. Analista no Ministério Público de Sergipe.E-mail: lucascarvalho.br@gmail.com

Flávia de Ávila Professora no Departamento de Relações Internacionais e no Programa de Pós-graduação em Direito da Universidade Federal de Sergipe (UFS). Doutora em Direito pela Pontifícia Universidade Católica de Minas Gerais (PUC Minas). Mestre em Direito e Relações Internacionais pela Universidade Federal de Santa Catarina (UFSC). E-mail: flaviadeavila@gmail.com 